\title{
ERRATUM
}

\section{Impact of maternal supplementation with probiotics during pregnancy on atopic eczema in childhood: a meta-analysis - ERRATUM}

Katja Doege, Donata Grajecki, Birgit-Christiane Zyriax, Elena Detinkina, Christine zu Eulenburg and Kai J. Buhling

(First published online 15 May 2012)

doi:10.1017/S0007114511003400, Published by Cambridge University Press, 12 October 2011

We made a mistake in Fig. 4 due to an abnormality in the order of the statistical parameters in the software (Stata 12.0 with ado-file metan)

Our statistician used an incorrect calculation by mistake:

(N_treat/(N_treat + N_contr)) : (event_treat/(event_treat + event_contr)

instead of:

(event_treat/N_treat) : (event_contr/N_contr)

The error does not have any impact on the results, but Fig. 4(a), (b) did not show the correct data. Here are the recalculated correct figures $^{(1)}$.

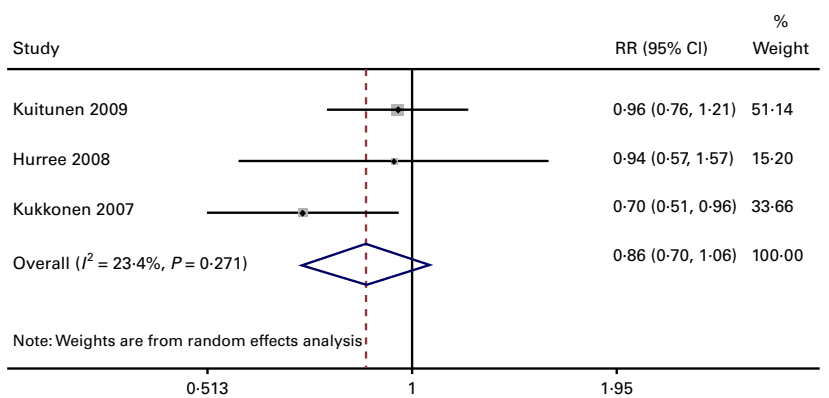

Fig. 4(a).

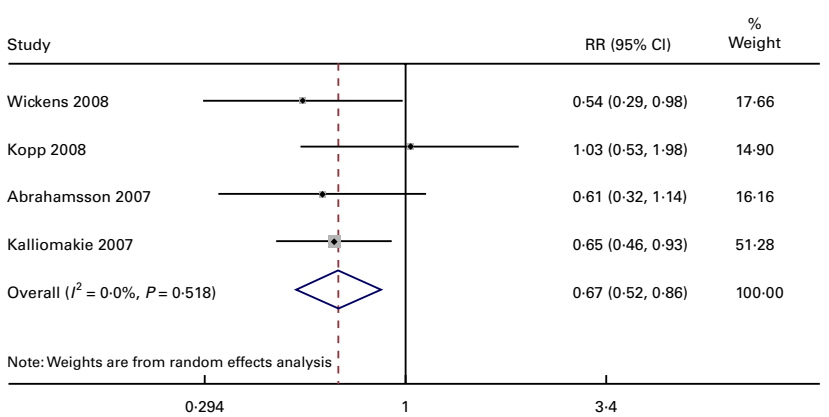

Fig. 4(b).

\section{Reference}

1. Doege K, Grajecki D, Zyriax B-C, et al. (2012) Impact of maternal supplementation with probiotics during pregnancy on atopic eczema in childhood: a meta-analysis. Br J Nutr 107, 1-6. 